\title{
A função sinestésica do jingle político
}

The sinestesic function of the political jingle

SILVIA THAIS DE POLI

Jornalista, Pós-graduanda em Sociologia Política pela Universidade Federal do Paraná e mestranda no Programa de Pós-Graduação Stricto Sensu em Comunicação e Linguagens pela Universidade Tuiuti do Paraná. thaisdepoli@hotmail.com

\section{Resumo}

0 objetivo deste artigo é apresentar um relato de pesquisa em desenvolvimento, referente à característica sinestésica do jingle político de candidatos à presidência do país em períodos relevantes da história política brasileira. Para tanto, será analisada a sinestesia encontrada na melodia do jingle e com isso, busca-se encontrar 'sentimentos' que correspondam às esperanças e aos desejos políticos da população de cada época determinada. Justifica-se essa pesquisa através da idéia de que os jingles políticos trazem 'sentimentos' em sua formação e que inseridos na melodia atuam de forma sinestésica, conquistando os ouvintes com a ilusão de que o candidato corresponderia aos anseios da população às necessidades sociais e emocionais de cada época histórica.

Palavras-chave: jingle político, sinestesia, comunicação política.

\section{Introdução}

Sendo uma peça publicitária de importante utilização, o Jingle Político esteve presente em diversas campanhas eleitorais na história política brasileira. Sua melodia contagiante embalava manifestaçôes a favor de candidatos que se apresentavam como a escolha ideal para a resolução dos problemas do cidadão.

Desde jingles memoráveis como os de Getúlio Vargas à reutilização parcial de jingles de antigas campanhas pelo atual presidente Lula, seu impacto está além da simples persuasão do voto. Melodias construídas com precisão agem de forma sinestésica no ouvinte resultando em uma resposta emocional à música apresentada. Através das três organizações, constituídas pelo ritmo, altura e harmonia, 'sentimentos' são transmitidos para o público que as responde com exaltação emocional e fidelidade.

Mas de que forma essas melodias eram construídas? Quais eram os 'sentimentos' presentes nessas canções? É possível que os jingles políticos refletissem as necessidades de uma sociedade, e fossem determinantes na escolha de um candidato?

\section{Metodologia}

Este trabalho inicia-se a partir da idéia de que a música, enquanto modo de comunicação, exerceu ao longo da história da humanidade o papel de construtora das relações interpessoais e mobilizadora cultural de cada novo período histórico que surgia. No entanto, a função social da música vai além da construção interpessoal e de mobilização cultural, pois ela detém o poder de determinar a moral de um povo (TAME, 1984, p. 19).

Para Roederer, na forma de experiência estética, a música demonstrase um meio de alcançar uma coerência comportamental em um grande grupo de pessoas. Segundo o autor, em um passado distante, essa função social da música teve seu valor de sobrevivência, já que o ambiente humano "cada vez 
mais complexo demandava ações coletivas coerentes por parte de grandes grupos da sociedade humana" (2002, p. 267).

Mais do que um fenômeno social destinado a manter as funções tradicionais em diferentes sociedades, no que diz respeito à evolução da espécie, a música exerce um papel fundamental criando cenários para os relacionamentos humanos (HURON apud ILARI, 2006, p. 192).

Dessa forma, é através da análise musical que podemos compreender aspectos sociais de uma sociedade, já que analisando as melodias é possível visualizar a situação vivenciada a respeito da vida política, econômica e social da época.

Para Merriam, música é definida como um meio de interação social produzida por especialistas - produtores - destinada a outras pessoas - receptores. Dessa forma, o fazer musical é entendido como um comportamento aprendido, através do qual sons são organizados, possibilitando uma forma simbólica de comunicação na inter-relação entre indivíduo e grupo. Para o autor, a música é um fenômeno humano capaz de existir apenas quando há interação social. Isso porque, ela atua tanto sobre o comportamento individual quanto social (1964, p. 27).

De forma mais específica ao estudo sobre Jingles Políticos, Hargreaves e North (1997) estipularam três funçôes psicológicas que atuam no comportamento individual: social, cognitiva e emocional.

Socialmente, os autores estipularam três domínios para o estudo. O primeiro domínio é vivido no contexto social e histórico, em uma dimensão coletiva onde o indivíduo recebe significações que são partilhadas socialmente e sentidos que são tecidos a partir dos significados compartilhados. Partindo do pressuposto de que a música se constrói pela ação do sujeito em relação direta com o seu contexto histórico-cultural, entendemos o sujeito como constituído e constituinte do contexto ao qual está inserido (WAZLAWICK et al, 2007, p. 106).

Com isso, passamos para o segundo domínio estipulado pelos autores: o estabelecimento de relações interpessoais. Nesta perspectiva, salienta Wazlawick, é preciso atentar para os aspectos "que permitem compreender que a música tem significado para cada pessoa na medida em que se vincula à experiência vivida, passada ou presente, $[. .$.$] quando proporciona ar-$ ticular o vivido junto aos sentimentos e emoções à própria música" (2007, p. 110).

A música, dessa forma, carrega um significado social, tanto por estar em relação com o contexto social quanto em possibilitar aos sujeitos a construção de múltiplos sentidos singulares e coletivos. Segundo Maheirie:

"O sentido da música (...) é sempre permeado pela afetividade. Em primeiro lugar, percebemos sua sonoridade, depois degradamos um saber anterior que tenha uma relação com os elementos percebidos deste som para, em seguida, transformarmos este saber e constituirmos um sentido àquela música. Posteriormente, estabelecemos, de forma singular, um significado para a música, compactuando ou não com seu significado coletivo. As características daquela sonoridade surgem como um complexo representativo que aparece determinado pela consciência afetiva, a qual, por sua vez, lhes dá nova significação". (2003, p. 150)

Essa consciência afetiva pode ser entendida como as emoções e os sentimentos do indivíduo, que interagem na atividade humana (juntamen- 
te com o pensar e agir) configurando na "construção dos significados singulares da música, de acordo com a sua própria reflexão acerca de si e de suas experiências". Para Wazlawick a música, ao despertar a afetividade, constrói a forma como o sujeito significa o mundo que o cerca. Ou seja:

"É de modo emocionado que o sujeito constrói os significados da música, em sua vivência, a partir de seus sentidos, objetivando sua subjetividade, tornando-a 'audivel'para ele e para os outros. Os significados e sentidos ressoam nas vivências do sujeito e são construidos na sua relação com a música. Estes significados partem das vivências afetivas do sujeito, demonstrando a utilização viva da música, uma vez que mudam, desconstroem-se e são recriados, porque também são constituidos pelos sentidos, ligados ao uso da música de modo idiossincrático e em relação". (WAZLAWICK et al., 2007, p. 112)

O terceiro e último domínio estipulado por Hargreaves e North relativo à função social da música em contextos culturais é a regulamentação do humor.

Para Crozier, a música contribui na influência social em virtude de sua capacidade de induzir afeto. Sua importância se deve aos processos determinados na relação entre música e afeto como tomada de decisão, formação de uma primeira impressão, formação de julgamentos relativos a membros de um mesmo grupo, mensagens persuasivas, entre outros (1999, p. 74).

No que refere à regulamentação do humor e dos estados emocionais, Bruner acredita que diferentes tipos de músicas induzem a diferentes tipos de humor, dependendo da contextualização social em que o indivíduo se encontra no momento. Segundo pesquisas realizadas pelo autor pode ser constatado que:

"A excitação é produzida por músicas que possuem modulação alta e rápida, com um pitch médio, ritmo desigual, harmonia dissonante e volume alto. A sensação de tranqüilidade é produzida por músicas que possuem modulação alta, ritmo fluente, pitch médio, harmonia consoante e volume 'calmo'. Felicidade é induzida a partir de modulação alta, com alto pitch, com um ritmo fluente, harmonia consoante e volume médio. Música séria é composta de modulação alta, com pitch baixo e monódico, ritmo lento, harmonia consoante $e$ volume médio. A tristeza é produzida em modulação baixa, baixo tempo, entonação monódica, com ritmo fixo e harmonia dissonante". (apud CROZIER, 1999, p. 75)

Para Crozier, a regulamentação do humor é apenas mais uma ferramenta utilizada com o propósito de induzir o afeto. Para o autor, é através do ritmo e do tempo que se estimula o ouvinte, provocando a regulamentação do humor e influenciando o seu comportamento.

Emocionalmente, por ser uma forma de comportamento humano, a música tem a capacidade de exercer uma influência única e poderosa sobre o indivíduo. Seja qual for o seu propósito - de alegria, tristeza, exaltação cívica, recolhimento, religioso - a música se relaciona com o seu criador, o homem, de forma mágica.

Segundo Ingeñieros, nascida da mente e das emoções do homem, a música "não cria coisa alguma, mas sim intensifica como se fosse um ressoador que reforçasse, em cada indi- 
víduo, aquilo que já existe nele". E conclui que a música pode tanto despertar o mais nobre sentimento, alterar o humor, acalmar e modificar a conduta, entre outros como induzir a estados hipnóticos (apud LEINING, 1977, p. 21).

Sendo uma forma de cognição, a sinestesia é conceituada como a interrelação de todos os sentidos. Trata-se de uma experiência pessoal, subjetiva, de forma que o indivíduo tem uma sensação vinculada a um determinado sentido, gerado a partir de um estímulo a outro sentido diverso.

O estudo da sinestesia pode se revelar fundamental para se compreender a relação entre conhecimento objetivo e subjetivo, sobre os mecanismos perceptivos e cognitivos do ser humano e sobre o funcionamento do cérebro. Suas implicações se referem diretamente sobre os aspectos da percepção, das relações entre razão e emoção, sobre a natureza da realidade, dos modelos de funcionamento do cérebro e da questão da natureza da consciência e de como as informações são inferidas pela percepção e outras estruturas cognitivas, resultando em uma "imagem consciente" mais ou menos coerente da realidade (BASBAUM, 2002, p. 30).

Partindo desses pressupostos, a escolha do jingle político se faz presente pela importância desta peça publicitária em diversas campanhas políticas, como em 1950 com Getúlio Vargas e o jingle "Bota o Retrato do Velho" ou ainda em 1989 com o jingle "Lula lá" do atual presidente Luis Inácio "Lula" da Silva. Será analisado ainda, o jingle "Varre, Varre Vassourinha" da campanha de Jânio Quadro.

O jingle político é uma peça publicitária e como tal, possui características da Propaganda. De forma geral, a Propaganda tem por objetivo determinar a convicção de consumir, relacionando sentimentos à idéias, esti- mulando o desejo de garantir valores almejados pelo seu público-alvo. Além disso, o jingle é um das formas utilizadas para se alcançar a coerência comportamental necessária além de apresentar o candidato como a solução para as necessidades do cidadão, segundo Sampaio:

"As pessoas ouvem e não esquecem. É aquilo que a sabedoria popular denomina de "chiclete de orelha". A vantagem dos jingles, em razão do formato, é que essas peças musicais contém, além da mensagem, o clima, a emoção objetivada e um expressivo poder de "recall". O jingle é algo que fica, uma vez que as pessoas guardam o tema consigo e muitos anos depois ainda são lembradas pelos consumidores. Devido ao poder de memorização que a música tem, o jingle é uma alternativa de comunicação muito poderosa. Sua única limitação é que, por ser música e ter que seguir uma métrica, às vezes não se consegue colocar na peça todas as informaçôes desejadas pela campanha publicitária”. (2003, p. 79)

Na primeira organização, referente ao comprimento, o ritmo é o elemento principal. Freqüentemente associado à dimensão horizontal, se associa diretamente ao tempo e a intensidade da música. Dessa forma, o Ritmo são os sons e silêncios que se sucedem temporalmente - cada som e silencio com duração e intensidade própria. $\mathrm{O}$ Ritmo pode ser periódico, obedecendo a uma pulsação definida ou mesmo a uma estrutura métrica. Pode haver ainda diversos ritmos que se sobreponham na mesma composição, chamada de polirritmia, assim como pode ser livre e não periódico e não estruturado, denominado arritmia. Des- 
sa forma, a variação de intensidade ao longo da canção compõe a dinâmica musical.

Em relação à segunda organização, ela pode ser visualmente concebida como a dimensão vertical através da altura. A nota mais aguda, de maior frequiência é denominada 'mais alta'. Em contraponto, o mais grave é o mais baixo. $\mathrm{O}$ elemento que organiza as alturas é a melodia. Definida como a sucessão de alturas ao longo de tempo, ela organiza a duração e a intensidade que se sobrepõem caracterizando o ritmo.

A terceira organização é a harmonia ou polifonia. Visualmente, ela pode ser considerada como a profundidade. É definida como a execução simultânea de várias melodias que se sobrepōem, como se estivessem em camadas, e a harmonia estivesse sobreposta a todas elas.

A composição musical de um jingle político geralmente segue um compasso simples, de ritmo popular, sem grandes 'agudos' e 'baixos', permitindo que qualquer pessoa cante ou assobie sua melodia. Por ter poucos versos, se torna repetitivo, o que torna sua musicalidade fácil de ser assimilada e de fácil execução. Geralmente, é composto de poucos versos. Ao relacionar a fantasia com a realidade e isso à capacidade de persuasão, o jingle transmite emoção e beleza de forma rápida e compacta ao ouvinte. Como é o caso dos jingles citados no início desse relato de pesquisa.

\section{Resultados}

O jingle de Vargas - "Bota o Retrato do Velho" - é composto em ritmo de marcha, com 12 versos. O jingle "Lula lá", em ritmo de valsa, também tem 12 versos. A sinestesia, no entanto, é compreendida apenas quando se escuta as canções.
Enquanto a de Vargas transmite alegria e felicidade - devido ao seu ritmo de marcha de carnaval e sua composição - o jingle de Lula transmite uma mensagem romântica, de esperança. No caso de Vargas a alegria se referia a volta à cena política depois de tantos anos, e no caso de Lula, a esperança de se conquistar a presidência apesar da origem humilde do candidato.

Finalizando, o jingle político atua em uma eleição com o princípio de construir as relações interpessoais, além de ser capaz de mobilizar um grande grupo de pessoas a favor de uma idéia. Sua influência está fortemente ligada com aspectos sociais, cognitivos e emocionais do indivíduo, o que o torna imprescindível para o marketing político de um candidato. A sinestesia neste caso, por sua vez, age a partir de um estímulo auditivo reagindo emocionalmente no indivíduo, levando-o a ação. É justamente da sinestesia desses poucos versos que às vezes se determina a história política do país.

\section{Abstract}

The objective of this article is going to present an account of research in development, regarding the characteristic sinestesica of the political jingle of candidates to the presidency of the country in prominent periods of the Brazilian political history. For so much, it will be analyzed to sinestesia found in the melody of the jingle and with that, search be found 'feelings' that correspond to the hopes and to the political desires of the population of each determined epoch. Justifies-itself that research through the idea of that the political jingles bring 'feelings' in his formation and that inserted in the melody act of form sinestesica, conquering the listeners with the illusion of that the candidate would correspond to the yearnings of the population to the emotional and social needs of each historical epoch.

Key-words: political jingle, sinestesia, political communication. 


\section{Bibliografia}

BAUSBAUM, Sérgio Roclaw. Sinestesia, Arte e Tecnologia. Fundamentos da Cromossonia. São Paulo: Annablume, 2002.

CROZIER, W. Roy. Music and social influence. In: The Social Psychology of Music. Oxford: Oxford University Press, 1999

HARGREAVES, David; NORTH, Adrian. The Functions of Music in Everyday Life: Redefining the Social in Music Psychology. Psychology of Music and Music Education, Oxford, v. 27, 1999, p. 71-83.

ILARI, Beatriz. Música, Comportamento Social e Relaçôes Interpessoais. Psicologia em Estudo. Maringá, v. 11, n. 1, p. 191-198, jan./abril. 2006.

LEINING, Clotilde E. Tratado de Musicoterapia. São Paulo: Sobral, 1977.

MAHEIRIE, K. Processo de criação no fazer musical: uma objetivação da subjetividade, a partir dos trabalhos de Sartre e Vygotsky. Psicologia em Estudo, v. 8, p. 147-153, 2003.

MERRIAM. Alan. The Anthropology of Music. Northwestern University Press, 1980.

ROEDERER, Juan G. Introdução à Física e Psicofísica da Música. São Paulo: Ed. da Universidade de São Paulo, 2002.

SAMPAIO, R. Propaganda de $A$ a $Z$ : como usar a propaganda para construir marcas e empresas de sucesso. 3. ed. Rio de Janeiro: Campus, 2003.

TAME, David. O Poder Oculto da Música: Um estudo da influencia da música sobre o homem e sobre a sociedade, desde o tempo das antigas civilizaçôes até o presente. São Paulo: Cultrix, 1984.

WAZLAWICK, Patrícia, CAMARGO, Denise, MAHEIRIE, Kátia. Significado e Sentidos da música: uma breve "composição" a partir da Psicologia HistóricoCultural. Psicologia em Estudo, Maringá, v. 12 , n. 1, p. 105-113, jan./abr. 2007.

Data do recebimento: $17 / 10 / 2007$ Data do aceite: $23 / 11 / 2007$ 